Preprint

UCRL-JC-141835

\title{
Carbon Resistor Pressure Gauge Calibration at Low Stresses
}

\author{
B. Cunningham, K. S. Vandersall, A. M. Niles, D. W. \\ Greenwood, F. Garcia, J. W. Forbes
}

This article was submitted to $12^{\text {th }}$ American Physical Society Topical Conference, Atlanta, GA., June 24-29, 2001

\section{June 22, 2001}

Lawrence

Livermore

National

Laboratory

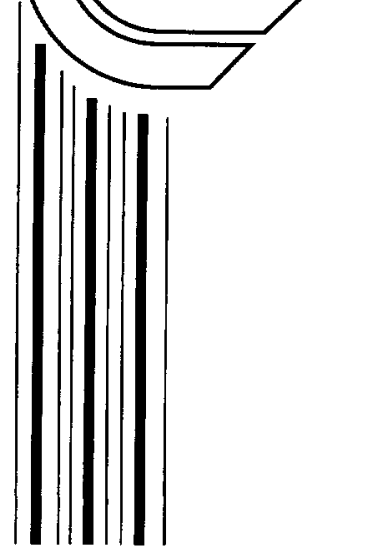




\section{DISCLAIMER}

This document was prepared as an account of work sponsored by an agency of the United States Government. Neither the United States Government nor the University of California nor any of their employees, makes any warranty, express or implied, or assumes any legal liability or responsibility for the accuracy, completeness, or usefulness of any information, apparatus, product, or process disclosed, or represents that its use would not infringe privately owned rights. Reference herein to any specific commercial product, process, or service by trade name, trademark, manufacturer, or otherwise, does not necessarily constitute or imply its endorsement, recommendation, or favoring by the United States Government or the University of California. The views and opinions of authors expressed herein do not necessarily state or reflect those of the United States Government or the University of California, and shall not be used for advertising or product endorsement purposes.

This is a preprint of a paper intended for publication in a journal or proceedings. Since changes may be made before publication, this preprint is made available with the understanding that it will not be cited or reproduced without the permission of the author.

This work was performed under the auspices of the United States Department of Energy by the University of California, Lawrence Livermore National Laboratory under contract No. W-7405-Eng-48.

This report has been reproduced directly from the best available copy.

Available electronically at http://www.doc.gov/bridge

Available for a processing fee to U.S. Department of Energy And its contractors in paper from

U.S. Department of Energy

Office of Scientific and Technical Information

P.O. Box 62

Oak Ridge, TN 37831-0062

Telephone: (865) 576-8401

Facsimile: (865) 576-5728

E-mail: reports@adonis.osti.gov

Available for the sale to the public from

U.S. Department of Commerce

National Technical Information Service

5285 Port Royal Road

Springfield, VA 22161

Telephone: (800) 553-6847

Facsimile: (703) 605-6900

E-mail: orders@ntis.fedworld.gov

Online ordering: http://www.ntis.gov/ordering.htm

OR

Lawrence Livermore National Laboratory

Technical Information Department's Digital Library

http://www.llnl.gov/tid/Library.html 


\title{
CARBON RESISTOR PRESSURE GAUGE CALIBRATION AT LOW STRESSES
}

\author{
Bruce Cunningham, Kevin S. Vandersall, Angela M. Niles, Daniel W. Greenwood, \\ Frank Garcia, and Jerry W. Forbes
}

Lawrence Livermore National Laboratory, 7000 East Avenue L-282, Livermore, CA 94550

\begin{abstract}
The $470 \mathrm{Ohm}$ carbon resistor gauge has been used in the stress range up to approximately 4-5 $\mathrm{GPa}$ for highly heterogeneous materials and/or divergent flow experiments. The attractiveness of the gauge is due to its rugged nature, simple construction, low cost, reproducibility, and survivability in dynamic events. The associated drawbacks are a long time response to pressure equilibration and gauge resistance hysteresis. In the range below $0.4 \mathrm{GPa}$, the gauge calibration has been mainly extrapolated into this regime. Because of the need for calibration data within this low stress regime, calibration experiments were performed using a split-Hopkinson bar, drop tower apparatus, and a gas pressure chamber. Since the performance of the gauge at elevated temperatures is a concern, the change in resistance due to heating at atmospheric pressure was also investigated. Details of the various calibration arrangements and the results will be discussed and compared a calibration curve fit to previously published calibration data.
\end{abstract}

\section{INTRODUCTION}

The carbon resistor gauge has previously been studied by numerous researchers $[1-8]$ in several different initial resistances values. This gauge is essentially a simple carbon composition resistor that can be used as a pressure gauge with little or no modification. The only equipment needed is a power supply to provide a small amount of constant current. Because of the ease of use, ability to measure pressures in the range up to 3-5 GPa, and survivability in harsh environments, it can be used in cases where no other gauge would survive. However, because the gauge is manufactured to act simply as a resistor and not as a pressure gauge, a calibration that is empirical in nature would seem evident. Because of this, the gauge is generally described as having only approximately $15 \%$ accuracy.

Recent experiments at Lawrence Livermore National Laboratory (LLNL) [9-10] have incorporated using the $470 \Omega$ carbon resistor gauge in energetic materials that often make measurements in the range of 3-5 GPa and at times in the low-pressure regime less than $0.4 \mathrm{GPa}$. In the case of the $470 \Omega$ carbon resistor gauge, Bill Wilson at Eglin Air Force Base fit previous data to a calibration curve [11]. This curve is mainly extrapolated into the low pressure regime from data collected at higher pressures. Thus, the goal of this work is to characterize the calibration of the $470 \Omega$ carbon resistor gauge at low pressures $(<0.6 \mathrm{GPa})$ using a static gas pressure chamber (argon environment, a split-Hopkinson bar, and a drop tower apparatus. Because some experiments require heating of the experiment assembly, investigating the behavior of the resistor at ambient pressure as it is heated was also performed.

\section{EXPERIMENTAL PROCEDURE}

The resistors used in this work were standard $1 / 8$ Watt, $470 \Omega$ carbon composition resistors made by Allen-Bradley Corporation. The nominal dimensions of the resistor are $1.7 \mathrm{~mm}$ diameter and $4 \mathrm{~mm}$ long, with wire leads extending from each side of the length of the cylinder. The details of the procedure for each calibration as well as the results 
for that calibration are included in the respective sections below. During each experiment the constant current power supply for the carbon resistor gauges remained on at all times and supplied $\sim 16 \mathrm{~mA}$ of constant current through the $470 \Omega$ resistor gauges.

\section{Static Gas Pressure Chamber}

The static gas pressure calibrations of the carbon resistor gauge were performed in a pressure chamber that is usually used to measure burn rates of enegetic materials at elevated temperatures and pressures. Further details of the apparatus are included elsewhere [12]. Figure 1 outlines a general schematic of the assembly used. The chamber has a capability to be pressurized to $0.4 \mathrm{GPa}$ with pressurized gas (in this case argon). As indicated in Figure 1, a calibrated Kistler model $6213 \mathrm{~B}$ quartz gauge [13] is located at one end of the chamber to measure the pressure in the chamber and the carbon resistor gauge array (5 gauges) are located at the other end. During the loading in the experiment the output from the gauges are continuously scanned on a Keithly digital voltmeter and saved on a computer.

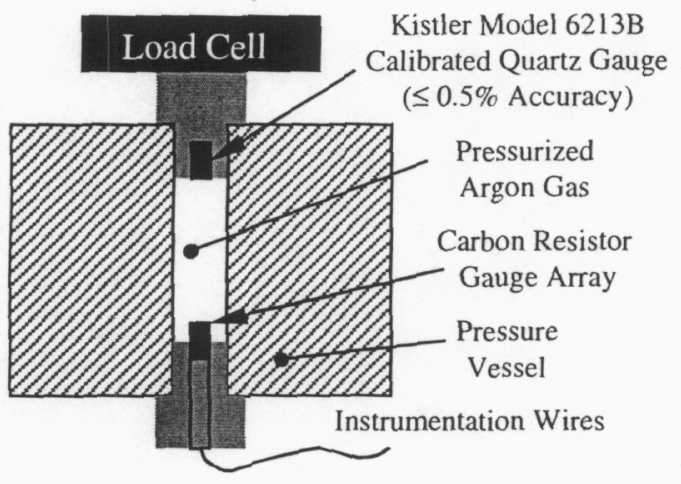

Figure 1. Schematic outlining the gas pressure chamber assembly.

\section{Split-Hopkinson Bar}

Calibration experiments were performed using a split-Hopkinson bar apparatus. Details of the operation of the split-Hopkinson pressure bar can be found in associated references [14-15]. Figure 2 (a) shows a schematic of the apparatus which consists of a striker bar impacting an incident bar that is adjacent to the sample and backed by a transmitted bar. The bars are operated in the elastic regime and strain gauges placed on the input and transmitted bars measure the input and transmitted strains, thus the input and transmitted stresses can be calculated using the elastic modulus of the bar material. Bars made from $9.5 \mathrm{~mm}$ diameter 6061-T6 aluminum were used in these calibration experiments. Figure 2 (b) outlines the schematic carbon resistor gauge arrangement that consisted of two sample halves that are $7.6 \mathrm{~mm}$ diameter by $2.5 \mathrm{~mm}$ and $5 \mathrm{~mm}$ thick respectively. The carbon resistor gauge was placed in grooves in the larger sample half, and then the sample was joined together with Dow Corning 3145 RTV sealant. For the analysis, the sample stress was calculated by using the transmitted stress in the transmitted bar (calculated from the peak strain) multiplied by the ratio of the aluminum bar diameter to the final Teflon sample (with embedded gauge) diameter. A Tektronix TDS $784 \mathrm{D}$ oscilloscope was used to measure the carbon resistor gauge output during the experiment.

a)

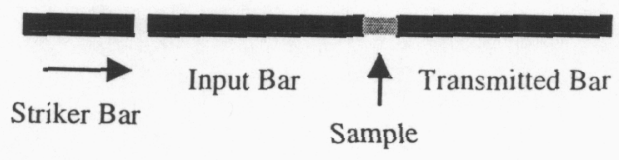

b)

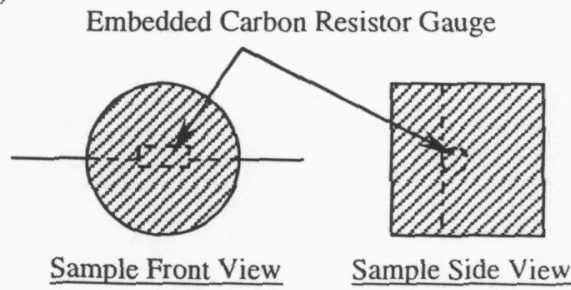

Figure 2. Schematic showing (a) split-Hopkinson bar arrangement and (b) general illustration of carbon resistor gauge ( $\sim \mathrm{mm}$ long by $1.7 \mathrm{~mm}$ diameter) in Teflon sample.

\section{Drop Weight Apparatus}

A commercially available drop weight apparatus, model 913B02 Hydraulic Impulse Calibrator, obtained from PCB, Piezotronics [17] was used. Figure 3 shows a schematic of the apparatus with a $4 \mathrm{~kg}$ drop weight dropped from different heights $(0.1,0.41,0.71,1.18$, and 1.49 meters $)$ which impacts a plunger assembly that creates hydraulic 
pressure in the silicone fluid (Dow 200 silicone oil, 20 centistokes viscosity [16]). Both the calibrated PCB Piezotronics model 136A [17] quartz reference transducer and carbon resistor pressure gauge sample were placed at mirror sides of the fluid to make measurements. A PCB model 443A101/443A102 dual mode amplifier was used to amplify the calibrated gauge signal and a Tektronix TDS 784D oscilloscope was used to measure the carbon resistor gauge output during the experiment. In the analysis, the peak value from the calibrated pressure gauge was correlated to the peak resistance change from the carbon resistor gauge which both correlated well in time.

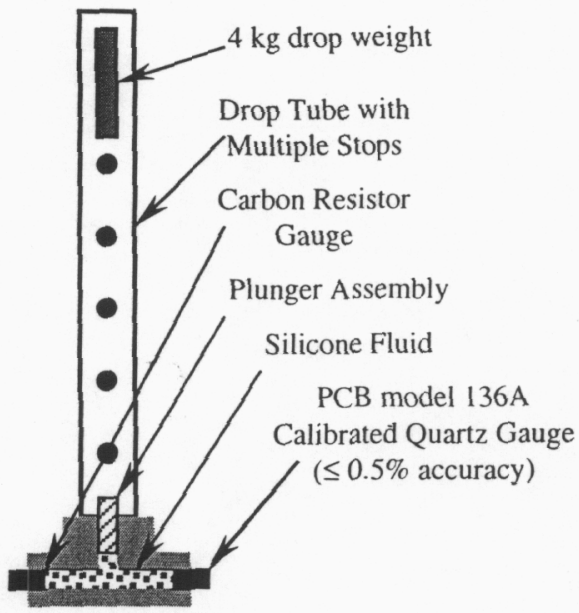

Figure 3. Schematic showing the drop weight carbon resistor gauge calibration set-up.

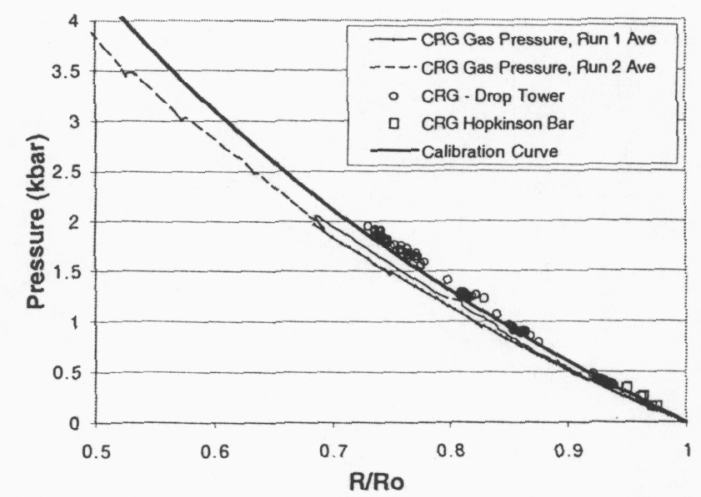

Figure 4. Summary plot of the carbon resistor gauge calibration compared with the calibration curve fit to previously published data.

\section{Investigation of Heating at Atmospheric Pressure}

The effect of heating at atmospheric pressure on the carbon resistor pressure gauge was investigated by placing an array of resistors in an oven and heated in air to $160^{\circ} \mathrm{C}$. During the heating the carbon resistor gauge resistance was continuously scanned on a Keithley digital ohmmeter and output to a computer that recorded the resistance value of the gauges and the thermocouple voltage.

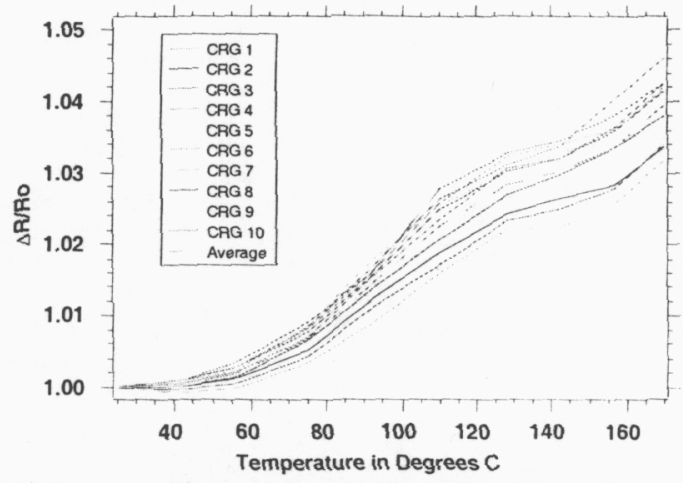

Figure 5. Change in resistance as a function of temperature (at atmospheric pressure) for 10 carbon resistor gauges. Note the dashed line is the average value.

\section{DISCUSSION}

Figure 4 shows a summary plot of the results as compared with the calibration curve fit to previously published data. Two runs of the gas pressure chamber data to 0.4 and $0.2 \mathrm{GPa}$ are shown as an average of the array of 5 resistors. The average value was used due to little variation between each individual resistor. The splitHopkinson bar data is shown as open squares and the drop tower data is shown as open circles. It should be noted that with the drop tower data, some of the points were obtained from multiple drops on the same resistor with no observable deviation. This is another indication of the rugged nature of the carbon resistor gauge. In this summary plot, the gas pressure chamber data shown falls slightly below the dynamic curve and would be expected due to the static nature of the loading, while having the calibration curve based on dynamic loading. As for the remaining calibration experiments, the points follow the curve reasonably well. Figure 5 
displays the relationship of temperature on the resistance change of the carbon resistor gauge. From this plot it can be seen that only a $4 \%$ change on average and a $1.4 \%$ difference among groups when heated to $160^{\circ} \mathrm{C}$ is observed.

\section{SUMMARY AND FUTURE WORK}

Calibration experiments were performed at low stressed $(<0.4 \mathrm{GPa})$ to compare the results of the carbon resistor pressure gauge with a calibration curve fit to previously published calibration data using a split-Hopkinson bar, drop tower apparatus, and gas pressure chamber. The gas pressure chamber data falls slightly below the dynamic curve as might be expected due to differences in static and dynamic loading. For the most part, the calibration experiments using dynamic loading follow the previously published calibration curve reasonably well. Gas gun experiments are in progress to extend the current low-pressure region up to $\sim 1.6 \mathrm{GPa}$, as well as experiments at elevated temperature $\left(\sim 80^{\circ} \mathrm{C}\right)$. The behavior of the carbon resistor gauge with temperature was shown to only vary $4 \%$ on average when heated up to $160^{\circ} \mathrm{C}$ at atmospheric pressure.

\section{ACKNOWLEDGEMENTS}

Jerry Dow is thanked for providing the funding for the research. Douglas Tasker (LANL) and William Wilson (Eglin AFB) are acknowledged for sharing their information on the use of the carbon resistor gauge. The carbon resistor gauge constant current power supply was designed by Douglas Tasker. This work was performed under the auspices of the United States Department of Energy by the Lawrence Livermore National Laboratory under Contract NO. W-7405-ENG-48.

\section{REFERENCES}

1. R.W. Watson, Rev. Sci. Instrum. 38, 978 (1967).

2. J. Stankewicz and R.L. White, Rev. Sci. Instrum. 42, 1067 (1971).

3. Ginsberg, Michael J., and Asay, Blaine W., "Commercial Carbon Composition Resistors as Dynamic Stress Gauges in Difficult Environments," Rev. Sci. Instrum. 62 (9): 2218-2227 (1991)

4. Wilson, W. H., "Experimental Study of Reaction and Stress Growth in Projectile-Impacted Explosives," Shock Compression of Condensed Matter-1991, eds. Schmidt,
Dick, Forbes, and Tasker, Elsevier Science Publishers, pp. 671-674 (1992).

5.W.M. Wilson, D.C. Holloway, and G. Bjarnholt, Techniques and Theory of Stress Wave Measurements for Shock Wave Applications (American Society of Mechanical Engineers, New York, 1987), pp. 97-108.

6. Austing, J. L., Tulis, A. J., Hrdina, D. J., and Baker, D. E., "Carbon Resistor Gauges for Measuring Shock and Detonation Pressures I. Principles of Functioning and Calibration, Propellants, Explosives, Pyrotechnics 16, pp. 205-215 (1991)

7. A.J. Tulis, J.L. Austing, D.E. Baker, and D.J. Hrdina, Propellants, Explosives, Pyrotechnics, 16, 216-220 (1991).

8. J.L. Austing, A.J. Tulis, R.P. Joyce, C.E. Foxx, D.J. Hrdina, and T.J. Bajzek, Propellants, Explosives, Pyrotechnics, 20, 159-169 (1995).

9. Frank Garica, Jerry W. Forbves, Craig M. Tarver, Paul A. Urtiew, Daniel W. Greenwood, and Kevin S. Vandersall, "Pressure Wave Measurements from Thermal Cook-off of an HMX Based High Explosive PBX 9501," 12trh APS Conference on Shock Compression of Condense Matter, Atlanta, GA, June 245-29, 2001, this proceedings.

10. A.M. Niles, F. Garcia, D.W. Greenwood, J.W. Forbes, C.M. Tarver, S.K. Chidester, R.G. Garza, and L.L. Switzer, "Measurement of Low Level Explosives Reaction in Gauged Multi-dimensional Steven Impact Tests," 12trh APS Conference on Shock Compression of Condense Matter, Atlanta, GA, June 245-29, 2001, this proceedings.

11. William H. Wilson, Eglin Air Force Base, Private Communication to Jerry W. Forbes.

12. J.L. Maienschein and J.B. Chandler, "Burn Rates of Pristine and Degraded Explosives at Elevated Pressures and Temperatures," $11^{\text {th }}$ International Symposium on Detonation, p. 872.

13. Kistler Instrument Corporation, 75 John Glenn Drive, Amherst, NY 14228-2171.

14. Follansbee, P.S., ASM Metals Handbook, Volume 8 Mechanical Testing, American Society of Metals, 1992, pp. 190-207.

15. R.M. Davies, "A critical Study of the Hopkinson Pressure Bar," Phil. Trans. A, vol. 240, 1948, pp. 375.

16. Dow Corning Corporation, Midland, Michigan 48686-0994

17. PCB Piezotronics, Inc., Buffalo, NY, 14225. 